\title{
https://doi.org/10.30853/manuscript.2019.11.64
}

\section{Алесенкова Виктория Николаевна}

\section{КОГНИТИВНОЕ ТЕАТРОВЕДЕНИЕ КАК ОПЫТ АНАЛИЗА МЕНТАЛЬНЫХ ПРОЦЕССОВ В}

КОНТЕКСТЕ ПОСТДРАМАТИЧЕСКОГО ТЕАТРА

Статья посвящена определению путей возможного развития нового направления в театроведении - когнитивного, под которым подразумевается изучение ментальных образов и мыслительных процессов на основе невербального языка сценического действия. Автор формирует комплексное представление о принципе творческого мышления в постдраматическом аспекте театрального искусства, демонстрируя его дихотомическую природу. В результате адаптации некоторых категорий когнитивной лингвистики и когнитивной психологии к реалиям театра театроведческий анализ дополняется такими инструментами, как мифический концепт, метасимвол и концептуальный символ.

Адрес статьи: www.gramota.net/materials/9/2019/11/64.html

\section{Источник}

\section{Манускрипт}

Тамбов: Грамота, 2019. Том 12. Выпуск 11. С. 341-345. ISSN 2618-9690.

Адрес журнала: www.gramota.net/editions/9.html

Содержание данного номера журнала: www.gramota.net/materials/9/2019/11/

\section{(c) Издательство "Грамота"}

Информация о возможности публикации статей в журнале размещена на Интернет сайте издательства: www.gramota.net

Вопросы, связанные с публикациями научных материалов, редакция просит направлять на адрес: hist@gramota.net 


\title{
Теория и история искусства
}

\author{
Theory and History of Art
}

\author{
УДК 792.01 \\ https://doi.org/10.30853/manuscript.2019.11.64
}

Дата поступления рукописи: 30.08.2019

Статья посвящена определению путей возможного развития нового направления в театроведении - когнитивного, под которым подразумевается изучение ментальных образов и мыслительных проиессов на основе невербального языка сиенического действия. Автор формирует комплексное представление о принципе творческого мышления в постдраматическом аспекте театрального искусства, демонстрируя его дихотомическую природу. В результате адаптации некоторых категорий когнитивной лингвистики и когнитивной психологии к реалиям театра театроведческий анализ дополняется такими инструментами, как мифический концепт, метасимвол и концептуальный символ.

Ключевые слова и фразы: когнитивное театроведение; творческое мышление; ментальные образы; постдраматический театр; метасимвол; мифический концепт; концептуальный символ; восприятие.

Алесенкова Виктория Николаевна, к. искусствоведения

Саратовская государственная консерватория имени Л. В. Собинова

alesenvic@gmail.com

\section{КОГНИТИВНОЕ ТЕАТРОВЕДЕНИЕ КАК ОПЫТ АНАЛИЗА МЕНТАЛЬНЫХ ПРОЦЕССОВ В КОНТЕКСТЕ ПОСТДРАМАТИЧЕСКОГО ТЕАТРА}

На фоне методологического кризиса в современной науке о театре, связанного с «новым использованием знаков» и «де-иерархизацией театральных выразительных средств» [8, с. 138-139] в постдраматическом аспекте сценического действия, исследование ментальных пространств спектакля становится тем более актуальным, чем более активно невербальная сфера театра развивается в ущерб нарративной. Невербальное сценическое действие, преобразованное из драматического в постдраматическое, или ритуальное действие, способно менять сущность вещей и влиять на зрительское мировосприятие, непосредственно участвуя в создании художественной картины мира, что в значительной степени объясняет необходимость модернизации театроведческого анализа в сторону когнитивного. Магистральной целью исследования является прокладывание путей развития оригинального метода анализа ментального пространства спектакля, который со временем может быть сформирован в методологию нового - когнитивного - направления в театроведении. Одной из важных задач становится конструктивная экстраполяция некоторых категорий из системы координат когнитивной лингвистики и когнитивной психологии в сферу театроведения для изучения мыслительных процессов, которые в постдраматическом дискурсе функционируют на более сложном уровне (по сравнению с драматическим) и до сих пор не попали в центр научного интереса. Научная новизна обусловлена целью исследования и заключается в применении междисциплинарного подхода для формирования понятийной базы когнитивного аспекта театрального процесса.

Когнитивная наука занимается «человеческим разумом и мышлением, и теми ментальными (мыслительными) процессами и состояниями, которые с ними связаны» [6, с. 58]. Если до сих пор театроведение ставило вопрос: как те или иные символы работают на концепцию режиссёра, - то теперь может быть заявлен вопрос о возможности изучения когнитивных процессов через создаваемые в спектакле концепты-символы. Целесообразность введения в обиход термина «когнитивное театроведение» обусловливается идентичностью предмета исследования когнитивной науки и той формы анализа, в которой нуждается театроведение для осмысления механизмов образования смысла и обнаружения форм познания действительности на основе невербального языка постдраматического театра. Под постдраматическим театром (в дополнение и расширение оригинальной концепции Х.-Т. Лемана [8]) подразумевается диалектическая модель творчества режиссёрахудожника, развивающаяся одновременно в направлениях мифотворчества и перформативности и отличающаяся способностью формировать смысл на ментальном неязыковом уровне зрительского восприятия.

Известно, что «восприятие» является одним из фундаментальных понятий когнитологии. Следовательно, с позиции когнитивной науки можно рассматривать зрительское восприятие спектакля (в его мифотворческом 
и перформативном аспектах) как процесс формирования нового смысла на основе нескольких базовых ментальных пространств, следуя теории концептуальной интеграции Ж. Фоконье и М. Тернера [15] или на основе пересечения смысловых пространств в терминологии Ю. Лотмана [9]. С этой точки зрения, в постдраматическом спектакле зрительское концептуальное пространство возникает на пересечении смысловых пространств автора и режиссёра, реализуясь на трёх уровнях восприятия сценического действия: формальном, ментальном языковом и ментальном неязыковом уровнях.

Можно предположить, что ментальный языковой уровень (область проявления значений) спектаклямифа соответствует понятию «языковое сознание», которое в терминологии 3. Поповой и И. Стернина является компонентом когнитивного сознания и отвечает за хранение языка: «...это часть сознания, обеспечивающая механизмы языковой (речевой) деятельности» [12, с. 32]. Возникающие в воображении зрителей ассоциативные связки, имея некоторое сходство с грёзами наяву, отличаются дискретной формой, однако даже по отдельным зафиксированным ассоциациям на основе одних и тех же сценических действий можно отчетливо различить, что зритель осмысливает информацию в языке как метатекст, и это позволяет отметить разницу в мыслительном процессе зрительской аудитории.

Учитывая при анализе не только профессиональные критические отзывы, но и, для объективности картины, результаты независимого опроса зрителей после просмотра спектакля Э. Някрошюса «Отелло» по пьесе У. Шекспира, было обнаружено, что процесс возникновения ассоциаций проходит в несколько этапов, если смысловые действия персонажей связаны с предметами. Сначала осуществляется автоматический перевод визуального плана в словесный: звон будильников - «время пришло», «час настал»; жестикуляция рук Яго - «сурдоперевод»; дверь на спине Дездемоны - «вход-выход»; белый и чёрный стулья Дездемона и Отелло. Затем, когда в мыслительный процесс включается нарративный элемент сцены или сюжета, область значений расширяется.

Звон будильников ассоциируется с неотвратимостью рока, судьбы, чёрный и белый стулья расширяют своё значение от персонажей до абстрактных понятий или концептов - добра и зла, правды и лжи, жизни и смерти, выводя состояние души Дездемоны на визуальный уровень метания между крайностями. Жесты рук Яго (Р. Казлас) у одной части зрителей преобразуются в психологические жесты (признак эмоционального напряжения, страха), тогда как у другой части - в смысловые (выражаемые невербальными метафорами и метонимиями: «просчитывает ходы», «играет на нервах», «вяжет замысел», «цепляется за идею», «плетёт паутину интриги»). Дверь с окошком на спине Дездемоны (Э. Шпокайте) в сцене прощания с отцом у большинства зрителей вырастает в ряд ассоциаций с переходом Дездемоны в иную (замужнюю, взрослую) жизнь, которая также коррелирует с тяжёлой ношей, крестом мученичества и даже с гробовой доской, что способствует возникновению парадигматических (основанных на действии) невербальных метафор и фразеологизмов: «закрыла дверь для прошлого»; «взвалила на себя тяжесть решения»; «похоронила себя для будущего»; «умерла для отца»; «принесла себя в жертву»; «взошла на Голгофу любви». Дверь, воспринятая как щит, панцирь или стена, рождает другое языковое осмысление: «между ними стена непонимания»; «душа Дездемоны - закрытая дверь»; «внутренний мир Дездемоны закрыт для отца и открыт для мужа». Дверь, воспринятая как перегородка в исповедальне, возводит отца в статус духовного наставника и, замещая разговор исповедью, включает мотив перехода из одной веры в другую.

В спектакле языковое сознание проявляется как метаязык на основе визуальных образов, и тем актуальней представляется изучение способов формирования мысли, которая, по Е. Кубряковой, используя «метафору, метонимию и “ментальную образность”» [6, с. 57], формирует концепт. Например, ряд невербальных метафор на основе образа двери в спектакле «Отелло» Някрошюса может стать частью концепта ПЕРЕХОДА, вмещающего комплекс представлений. Дверь, помимо упомянутых значений, можно рассматривать как объект сновидений (портал, мистический порог, двойственность внешнего и внутреннего состояния, связанного со страхами и открытиями новых пространств), как сказочный образ (дверь в замке Синей Бороды, дверь глупой Катерлизхен, дверь перед Алисой в Стране Чудес) и так далее.

В спектакле-мифе метафора репрезентируется номинальным символом, в который преобразуется иконический знак, а значит, экстраполяция принципов когнитивной лингвистики на невербальный язык театра ведёт к значительным изменениям в теории и выявит новые положения, а под «ментальной образностью» вполне могут мыслиться символические образы как «особые выражения жизни сознания» [10, с. 27]. Стимулирующим звеном в формировании концептов на основе театрального действия становится номинальный символ, т.к. он вмещает комплекс представлений на уровне языка и проецирует смысл на внеязыковой уровень, соединяя две реальности - внутреннюю и внешнюю, материальный и духовный миры, или эмпирический и метафизический (духовный) опыт.

Концепт с точки зрения структурализма (по Р. Барту) представляет собой вовсе не абстрактную сущность, а «конденсат неоформившихся, неустойчивых, туманных ассоциаций» [1, с. 84]. В отечественном языкознании (по Е. Зиновьевой) концепт утверждается как появившийся в сознании образ, который «способен продвигаться по ступеням абстракции... [и] постепенно превращается из чувственного образа в собственно мыслительный» [3, с. 37]. В теории Дж. Лакоффа и М. Джонсона «концепт структурирован метафорой» [7, с. 34], и адаптация понятия концептуальной метафоры к реалиям театра позволяет убедиться, что в процессе мифотворчества в постдраматическом театре концепт возникает как метафорический образ, который расширяется в символический.

\footnotetext{
${ }^{1}$ Театр “Meno Fortas” (Вильнюс, 2001 г.).
} 
Если принять во внимание позицию отечественных когнитологов: «Концепты возникают в процессе построения информации об объектах и их свойствах, причём эта информация может включать как сведения об объективном положении дел в мире, так и сведения о воображаемых мирах» [6, с. 90], - то становится очевидным, что концепт имеет отношение к спектаклю-мифу больше, чем к литературному тексту, потому что в структуре постдраматического мифа присутствует как ментальный языковой уровень (идентичный понятию «языкового сознания»), так и ментальный неязыковой уровень (идентичный понятию «мифического сознания»). Кроме того, наличие метафорической связи и символической проекции смысла способствует исследованию процесса мышления на основе создаваемых ментальных образов-символов.

Чтобы сформировать комплексное представление об аналитическом процессе мышления в театральном искусстве, следует провести ряд аналогий и выстроить систему координат когнитивного анализа.

Драматический театр, стремящийся к натуралистичности в выборе художественных средств, преимущественно оперирует синтагматическими связями по оси метонимии, а значит, индексальными знаками, в некотором роде игнорируя театральность в театральном искусстве. Ре-театрализация драматического действия выражается в стремлении к условности в выборе художественных средств, и тогда театр осваивает парадигматические связи по оси метафоры, отдавая предпочтение иконическим знакам, которые апеллируют к воображению зрителя.

Если очевидно, что значения индексальных, иконических и конвенционально-символических знаков в спектакле формируются в метатекст (отдельные невербальные метафоры, узнаваемые фразеологизмы, поговорки, понятия и реминисценции на ментальном уровне языка), то так же очевидно, что восприятие зрителей соответствует транссмысловой конструкции аллегорического типа. Следовательно, структуру спектакля можно определить как Миф I или Перформанс I (в зависимости от наличия признаков мифотворчества или перформативности). В обоих случаях к семантическому методу анализа присоединяется когнитивнолингвистический метод, поскольку концентрация невербальных метафор способствует созданию метафорических концептов. Конструирование или деконструкция смысла на аллегорическом уровне восприятия соответствует поэтическому (метафорическому) или постмодернистскому театру, задействует языковое мышление, апеллирует к эмпирическому опыту зрителя и представляет собой переходный этап от драмы к постдраме.

Если метатекст в векторе мифотворчества достигает такой концентрации значений, что невербальная метафора благодаря контексту развивается в образ, то объект-репрезентамен становится по отношению к ней номинальным символом, а образ-интерпретант - метасимволом. Наличие метасимвола свидетельствует о преобразовании сценического действия в действие символическое или сценический ритуал, который демонстрирует определённый сценарий трансформации образа для его осмысления. В работу включается конструкция мистериального типа, свойственная постдраматическому театру, которая задействует мифическое (или символическое) мышление и апеллирует к метафизическому опыту зрителя, следовательно, структуру спектакля можно определить как Миф II или Перформанс II, отвечающие спектаклю-мифу или спектаклюсну. Для понимания природы метасимвола следует обратиться к аналогии.

Метасимвол представляет собой ментальный символический образ, выделенный из сферы «бессознательного». В теории искусствознания это «бессознательное» соответствует области пересечения сфер «умопостигаемого и зримо-чувственного» Платона [11], сфер «высшей и низшей реальности» Вяч. Иванова [4], «невидимого горнего и видимого дольнего» миров П. Флоренского [13] и является идентификацией платоновской «веры», «полосы марев» Иванова и «сновидения» Флоренского, т.е. одновременным вместилищем имманентных человеческих и трансцендентных божественных образов.

Чтобы «невидимое» стало «видимым», аполлонические образы нисхождения и дионисийские образы восхождения воплощаются режиссёром при помощи театральных художественных средств и могут быть сравнимы с закладыванием «зерна мифа» (пользуясь термином Вяч. Иванова). Этим «зерном» становится метасимвол, который на благодатной почве театрального действия прорастает смыслом одновременно в двух направлениях, вниз и вверх, и познаётся зрителями как проекция метафорического концепта в концепт мифический, наглядно демонстрируя, что миф - это символ в действии. Направление творческого сознания художника определяет характер произведения и выражается в векторе мифотворчества или перформативности в «постижении сокровенной жизни сущего» $[4$, с. 270$]$, по Вяч. Иванову, или в дроблении, отказе от целого в пользу мелких параллелей. Здесь следует отметить, что кодирование смысла режиссёром и декодирование его зрителем находятся друг к другу в прямо противоположном направлении. Так, мифотворчеству свойственны образы нисхождения, а перформативности - образы восхождения, мышление зрителя действует в обратном порядке.

Модернизированная схематическая модель познания по Платону помогает наглядно продемонстрировать процесс творческого мышления, позволяя графически изобразить спиралевидный путь воплощения образа режиссёром и путь зрительского транссмыслового конструирования (см. Рисунок 1).

Так, режиссёрский «аполлонический образ», который есть не что иное, как Идея или Прообраз (D), «нисходит», отражаясь в области бессознательного («сновидения» или «веры») как метасимвол (В), который затем через осмысление в действии как мифический концепт $(\mathrm{C})$ преобразуется в концептуальный символ и становится осью проекции метафизического сценария в узнаваемый метафорический образ (А), для которого подбирается визуальная знаковая форма воплощения (F). C позиции мифотворчества ментальный образ (B) действительно становится, по Флоренскому, из горнего символом дольнего, а из дольнего символом горнего.

«Дионисийский образ» не предполагает предварительного подъёма сознания режиссёра в область созерцания Идей, а подразумевает обольщение абстрактным символическим образом из области «сновидения» (В) и дискретным осмыслением его действий в качестве архетипических ментальных схем трансформации (C), 
для которых, минуя языковую проекцию образа, режиссёр подбирает художественные средства воплощения (F), как правило, в форме смонтированных сценических ритуалов.

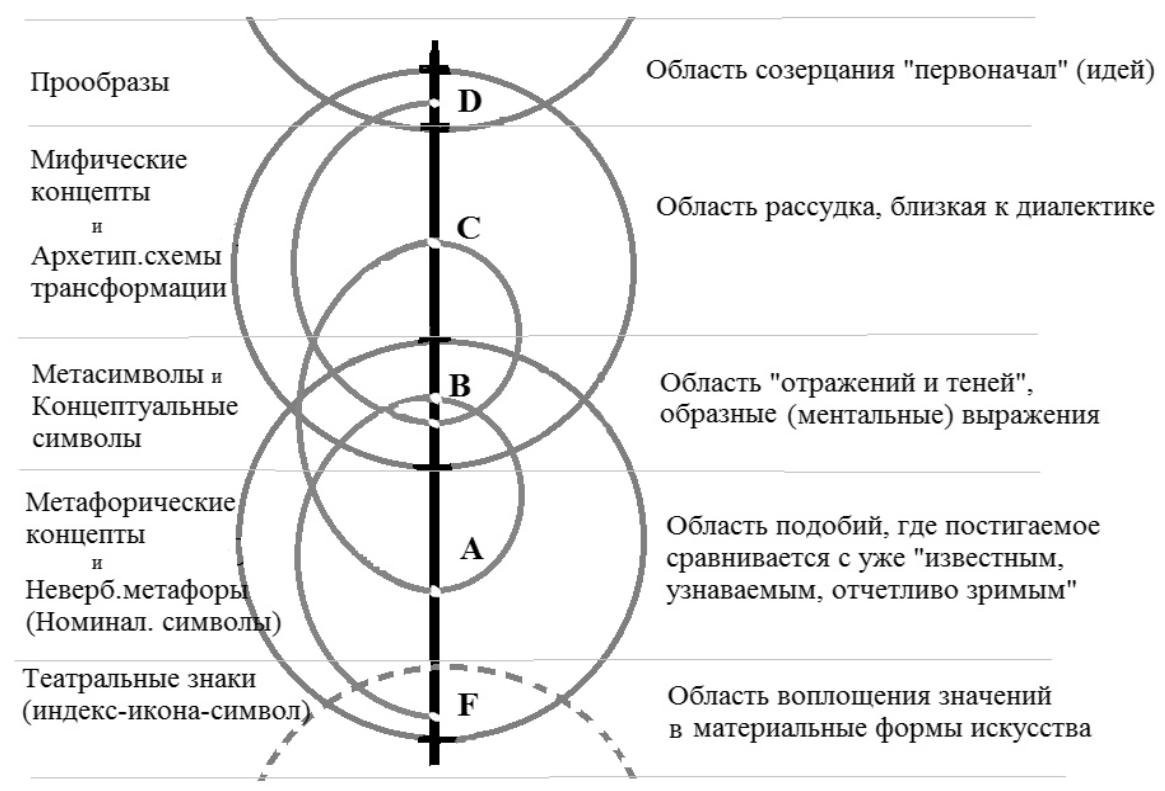

Рисунок 1. Схематическая модель процесса творческого мылиления

Здесь можно отметить, что постмодернистский путь творчества режиссёра отличается заимствованием чужого концептуального символа как исходного образа, ментальное языковое осмысление которого искажается в области (А) подменой традиционного смысла, для которого режиссёр находит адекватное новому контексту знаковое воплощение (F). В результате, зрительское восприятие попадает в ловушку бленда (наложение ментальных пространств в терминологии Ж. Фоконье и М. Тернера [15]), в котором осуществляется перекодировка отношения к исходному образу, разрушающая «устаревший» Миф.

Для зрителя в мифотворческом векторе постдраматического театра метасимвол по-лотмановски «мерцает» в воображении на основе номинального символа (Миф II строится на фундаменте Мифа I), поэтому может быть репрезентирован субъективным представлением. Образы государственности, власти, истины или инволюции становятся осью проекции между метафорическими и мифическими концептами в качестве концептуального символа, на основе которого познаётся Прообраз, отражённый в метасимволе. В то время как в перформативном векторе метасимвол творчески замещается в зрительском восприятии образом внутреннего человека (концептом ДУША), который играет роль концептуального символа и провоцирует зрителей на со-творение собственного мифа. Ввиду дефицита логических связей на ментальном уровне языка, декодирование смысла в Перформансе II следует начинать с архетипических схем трансформации (метафункций), дискретных подобий мифических концептов, заложенных в ментальном рисунке спектакля-сна.

В рамках вышесказанного можно предположить, что если зрительское конструирование смысла разворачивается по спирали и метафорическое мышление соответствует последовательности (F) - (B) - (A), а мифическое или символическое мышление соотносится с последовательностью $(\mathrm{A})-(\mathrm{C})-(\mathrm{B})$, то с большой долей вероятности существует и космическое мышление, которое отвечает последовательности (B) - (D) - (C).

B анализе сценария сакральной трансформации Прообраза заложен путь познания человека и миропорядка. Человек постигает божественное начало в себе через уподобление богам (по К. Ясперсу [14]), через Христа или Логоса (по Н. Бердяеву [2]), где логос можно трактовать (по Ф. Кессиди) как мир вещей, «взятый в двух аспектах: в аспекте внутреннего мира человека, его субъективности, и в аспекте внешнего строя вещей» [5, с. 218]. Следовательно, закономерно, что предметом мимесиса в мистериальном типе конструирования смысла становятся образы внутренней человеческой природы и внешней космической природы.

Подражание внутренней человеческой природе выражается посредством позитивного и негативного сценариев трансформации души, создавая представление о её метафизическом состоянии. Первый сценарий ассоциируется с возрождением Бога - обретением связей и переходом в духовную сферу, а второй - с искажением (демонической инверсией) или смертью Бога - обрывом вертикальных связей. Подражание внешней космической природе заложено в мифических концептах или архетипических схемах трансформации метасимвола и демонстрирует понимание универсальных метафизических законов. Именно в постдраматическом искусстве Логос может быть познаваемым через отражение в Мифе, который проявляется как метасимвол в действии.

Выявленные в театральных постановках мифические концепты ИЕРАРХИЯ, ВМЕЩЕНИЕ, РАВНОВЕСИЕ, ЦИКЛИЧНОСТЬ и ПОДОБИЕ представляют собой сценарии метафизических процессов преобразования вещей. Они интерпретируют функциональный или межпространственный порядок существования метафизических величин, выраженных мифическими концептами ЦЕЛОЕ, АМБИВАЛЕНТНОСТЬ, 
ТРИЕДИНСТВО, МНОЖЕСТВО, которые, будучи познанными в действии, из имманентных образов преобразовываются в трансцендентные.

В европейской культуре доминирующую роль в самопознании через искусство театра играет образ не одновременной (противоборствующие начала), а последовательной амбивалентности бытия, осмысляемый как чередование активности во множестве сценариев (спуск - подъём, построение - разрушение, свёртывание - развёртывание, уход - возвращение, притяжение - отталкивание, умирание - воскрешение), генерирующих энергию в различные мифические концепты. К слову, приведённый выше образ символа - «зерна», прорастающего смыслом вверх и вниз, включает интерпретацию «амбивалентности» как «вмещения», «равновесия» и «подобия» (как вверху, так и внизу). Все мифические концепты, или архетипические ментальные схемы трансформации, в идеале объединяются в общий неделимый закон преобразования энергии в космосе - Логос.

В заключение можно констатировать, что в статье намечены пути развития когнитивного театроведения, и они представляют собой метод анализа ментальных процессов на основе невербального сценического действия, безусловно, требуя дальнейшего изучения в контексте постдраматического театра. Важно отметить, что системным элементом конструирования смысла в спектакле становится символ, на основе которого формируются метафорические и мифические концепты. Дихотомическая природа воплощения (с позиции режиссера) и восприятия (с позиции зрителя) смысла в постдраматическом театре разворачивается по спирали и заключается в полярности векторов мифотворчества и перформативности.

На данном этапе исследования аналитический аппарат театроведения может быть дополнен новыми инструментами, присоединяя к феноменологическому (описательному) и семиотическому (структурному) методу анализа спектакля элементы когнитивной лингвистики (анализ концептов на основе сценических образов) и когнитивной психологии (анализ восприятия символов и сценариев трансформации образа), которые вкупе с искусствоведческим подходом к искусству как средству познания человека составят базу для развития когнитивного метода анализа. Важная задача когнитивного театроведения видится в определении природы воплощённых режиссёрами ментальных образов и возможности через их концептуализацию составить представление о качестве спектакля и последствиях его влияния на зрителей.

Список источников

1. Барт Р. Избранные работы. Семиотика. Поэтика. М.: Прогресс; Универс, 1994. 616 с.

2. Бердяев Н. Философия свободного духа. М.: Республика, 1994. 480 с.

3. Зиновьева Е. И. Понятие «концепт» в отечественном языкознании: основные подходы и направления исследования // Вестник Санкт-Петербургского университета. 2003. Серия 2. История. № 2. С. 35-44.

4. Иванов Вяч. Две стихии в современном символизме // Иванов Вяч. По Звёздам: сборник. СПб.: Оры, 1909. С. $247-308$.

5. Кессиди Ф. Х. От мифа к логосу (становление греческой философии). М.: Мысль, 1972. 312 с.

6. Кубрякова Е. С., Демьянков В. З., Панкрац Ю. Г., Лузина Л. Г. Краткий словарь когнитивных терминов / под общ. ред. Е. С. Кубряковой. М.: Филологический факультет МГУ им. М. В. Ломоносова, 1996. 245 с.

7. Лакофф Дж., Джонсон М. Метафоры, которыми мы живем / пер. с англ.; под ред. и с предисл. А. Н. Баранова. М.: Едиториал УРСС, 2004. 256 c.

8. Леман Х.-T. Постдраматический театр. М.: ABCdesign, 2013. 312 с.

9. Лотман Ю. М. Семиосфера. СПб.: Искусство-СПб, 2000. 704 с.

10. Мамардашвили М. К., Пятигорский А. М. Символ и сознание. Метафизические рассуждения о сознании, символике и языке. М.: Школа «Языки русской культуры», 1997. 224 с.

11. Платон. Государство. Тимей // Платон. Диалоги. Книга вторая. М.: Эксмо, 2008. С. 89-542.

12. Попова 3. Д., Стернин И. А. Когнитивная лингвистика: монография. М.: АСТ; Восток - Запад, 2007. 314 с.

13. Флоренский П. Иконостас. Избранные труды по искусству. СПб.: Мифрил; Русская книга, 1993. 365 с.

14. Ясперс К. Философия. Книга третья. Метафизика / пер. А. К. Судакова. М.: Канон+; РООИ «Реабилитация», 2012.296 с.

15. Fauconnier G., Turner M. Conceptual integration networks // Cognitive Science. 1998. Vol. 22. № 2. P. 133-187.

16. Fauconnier G., Turner M. The Way We Think: Conceptual Blending and the Mind's Hidden Complexities. N. Y.: Basic Books, 2002. 464 p.

\title{
COGNITIVE THEATRE STUDIES AS AN ATTEMPT OF ANALYZING MENTAL PROCESSES IN THE CONTEXT OF POST-DRAMATIC THEATRE
}

\author{
Alesenkova Viktoriya Nikolaevna, Ph. D. in Art Criticism \\ Saratov State Conservatoire \\ alesenvic@gmail.com
}

The article is devoted to identifying the prospects of a new trend in theatre studies - a cognitive one, which is considered as a study of mental images and mental processes on the basis of non-verbal theatrical language. The author develops a comprehensive conception of creative thinking in relation to post-dramatic theatre, which is dichotomic by nature. Adapting certain categories of cognitive linguistics and cognitive psychology to theatrical realia, the author introduces such notions as a mythic concept, a metasymbol and a conceptual symbol into a theatrological analysis.

Key words and phrases: cognitive theatre studies; creative thinking; mental images; post-dramatic theatre; meta-symbol; mythic concept; conceptual symbol; perception. 